\title{
INVESTIGATING HERITAGE SITES THROUGH THE LENS OF SOCIAL MEDIA
}

\author{
Leila MAHMOUDI FARAHANI ${ }^{1, *}$, Bahareh MOTAMED ${ }^{2}$, Maedeh GHADIRINIA ${ }^{3}$ \\ ${ }^{1}$ RMIT University, School of Global, Urban and Social Studies, Centre for Urban Research, Melbourne, Australia \\ ${ }^{2}$ Deakin University, School of Architecture and Built Environment, Australia \\ ${ }^{3}$ Iran University of Science and Technology, School of Architecture and Environmental Design, Iran
}

Received 28 May 2017; accepted 20 September 2018

\begin{abstract}
Today, our understanding and experience of heritage sites have been reframed by the advent of social media and the ubiquitous use of smartphones that offer more participatory ways of interacting with heritage. The lifespan of a heritage site is highly concerned with how it is understood and experienced by visitors. This study aims to investigate a heritage site and its participatory culture through the lens of social media and and to understand how a certain heritage site could be understood by these online networks. The historic city of Shiraz packed with several monumental buildings and heritage sites has been chosen as the case study of this research. Three social media platforms of Flickr, 500px and Instagram were investigated during 2015 and their photos of Shiraz were downloaded for analysis. The analysis of more than 186 images from these websites has provided an opportunity to investigate how the historical district of Shiraz is remembered in the eyes of social media users. Based on the initial photo audits, Nasir-al-Molk Mosque with more than 74 published images was the most published building and therefore was selected for an in-depth photo survey analysis. The Nasir-al-Molk Mosque images were studied regarding the physical and spiritual qualities of its building and how they contribute to its popularity among social media photographers.
\end{abstract}

Keywords: heritage, urban design, architecture, social media.

\section{Introduction}

Today, the use of affordable smartphones, cameras and the ease of access to free and available social media not only have resulted in new ways of interacting with heritage, but also have affected our experience and interpretation of heritage sites (King, Stark, \& Cooke, 2016). In this sense, the increasing volume of location-annotated data, archiving, proliferation and sharing images with others on various social media platforms such as Twitter, Instagram and Flickr provide a great opportunity to have immediate access to people's daily documentation of local activities, interests and attention to their environment and heritage sites. Images published in social media not only indicate users' interest about a particular perspective of a heritage site but also it embodies what photographers and social media users want to remember from the site in future. Additionally, posting these images may highlight and raise awareness about a heritage site or a specific part of a city, through reminding and jogging people's memories or generating a collective memory.
Shared pictures in the social media may also be referred to as a guide for tourists who are strangers to the city or the site. The angle of photography, the level of details and the perspective may have an impact on how people interpret a place or heritage site through pictures. Considering the heritage site an artistic and valuable object, photographers capture their own interpretation of the place, which can be different from what the creator originally intended. According to the theories of interpretation (hermeneutics), a picture taken from a heritage site is the result of its photographer's interpretation, which might be independent of the biographical context of the object/site. Therefore, different lenses may register different readings and expressions from a site. These individual interpretations shape a participatory culture which will be attached to a heritage site. Moreover, social media users may interpret images differently compared to photographers' intention, which will itself add to the participatory understanding of a heritage site. The availability of image editing tools should also be considered as an influential

${ }^{*}$ Corresponding author. E-mail: leila.farahani@rmit.edu.au 
factor that may affect perceptions of a heritage site. In this sense, manipulating colour contrast, adding a filter and cropping images not only may exaggerate the beauty of a place but also it may accentuate a heritage site in the collective memory of residents.

This study aims to analyse a heritage site and its participatory culture through the lens of social media. The historical district of Shiraz, which dates back to the Islamic era, has been selected as the case study. This district is packed with several monumental buildings of different types including mosques, bazaars, schools and houses. A careful investigation of published images of these heritage sites provides an opportunity to analyse how the old city of Shiraz is perceived and remembered in the eyes of social media users. The methodology of this research is an in-depth survey analysis of more than 186 photos that have been publicly published along 2015 in three social media websites (Flickr, 500px and Instagram), with a geotag in the historic district of Shiraz.

The analysis occurs in two stages. The first stage of the analysis seeks to identify heritage buildings and sites located in the old district of Shiraz based on the number of photos that have been geotagged and published in the selected social media websites. This analysis will result in the creation of a virtual map of historical places and represents how the old city has been perceived by photographers and at the same time specifies the neglected heritage sites that their images have not been published. The analysis of this map also reveals that a significant percentage of the published photos (40\%) have been geotagged in Nasir-al-Molk Mosque. Nasir-al-Molk Mosque, which is also known as the Pink Mosque and was built during the Qajar era, is one of the traditional mosques in the historical district of Shiraz and is still in use for its original religious function and also as a popular tourist attraction. Accordingly, in the second stage, Nasir-al-Molk Mosque will be explored in detail to examine what are the physical and spiritual qualities of this heritage site that contribute to its popularity among social media photographers in comparison to other historical buildings in the old district of Shiraz. This study aims to inform future work on tourism studies, heritage management studies, policy making and communication systems to conserve and preserve heritage sites for future.

\section{Social media}

"The only thing that is constant is change" (Andzulis, Panagopoulos, \& Rapp, 2012). The internet has dramatically changed existing means of communication, since it is now considered as the first choice for sending and receiving messages among people (Akpan, Akwaowo, \& Senam, 2013; Malita, 2011). The internet has shifted from being just an information access tool to an interaction tool (Heinrichs, J. H. Lim, \& K. S. Lim, 2011). It has benefitted its users to share and find useful information from all over the world (Anuradha, 2015). So, the advent of the internet has transformed various forms of sociability and interaction among users (Boyd \& Heer, 2005).
Over the recent years, the ubiquity and use of the internet have risen rapidly. The number of internet users has increased tenfold from 1999 to 2013 and is now about three and a half billion, looking to grow more and more in the next few years. The first billion was reached in 2005, the second billion in 2010 and the third billion in 2014 . Today the younger generations are highly tech-savvy and critical consumers of digital media. They are sometimes labelled as "digital natives" and the "net-generation" (Shaw \& Krug, 2013).

The term 'social media' appeared in the 1990s, based on the development of computer and internet technology (Treem \& Leonardi, 2012; Zhou \& Wang, 2014). Currently, dominant online platforms are uniformly termed 'social media' (Ariel \& Avidar, 2015) which have proliferated in the recent years (Tang, Wang, Hua, \& Chua, 2012).

Researchers have offered various definitions of the term 'social media' (Andzulis et al., 2012; Fotis, Buhalis, \& Rossides, N., 2012; Junco \& Chickering, 2010; Osatuyi, 2013; Treem \& Leonardi, 2012). Kaplan and Haenlein's (2010) definition is the most accepted and repeated definition in the literature: they have defined social media as "a group of Internet-based applications that build on the ideological and technological foundations of Web 2.0 and allow the creation and exchange of User Generated Content" (Kaplan \& Haenlein, 2010).

Social media or application of Web 2.0 is the evolution of Web 1.0 - the first stage of development of the World Wide Web (Munar \& Jacobsen, 2014). The second generation of the internet (Web 2.0) provides a lot of opportunities for communication in which people are able to interact with each other. Moreover, Web 2.0 can directly engage users in a creative process by both producing and distributing information through collaborative writing, content sharing, social networking, social bookmarking, and syndication (Malita, 2011).

Any form of user created media, "user generated content", is one of the key components of Web 2.0, which is published on a publicly accessible website or a website accessible to a selected group of people (Gruzd, Staves, \& Wilk, 2011). Wyrwoll (2014) explains: "User-generated content is content published on an online platform by users. The term social media comprises platforms that contain user-generated content. Users do not need programming skills to publish content on a social media platform".

Through social media, everyone is able to make an information publicly available without the need of a publisher (Wyrwoll, 2014). Much of daily reflections, communications and social interactions appear integrated as a part of social media network that have dramatically expanded the potential for human interaction (Chen \& Kelliher, 2011; Junco \& Chickering, 2010). The term 'social' in social media relates to three central concepts: information, interactivity, and sociability (Ariel \& Avidar, 2015). Social interaction plays a central role in social media context. Based on the existing literature, Shankar (2011) have generated a number of 'social interaction' factors such as: social activities, social presence, sense of 
belonging, object centeredness, mode of relationship, facilitation, lack of immediacy/connectivity, sense of time/ space and flexibility, lack of verbal and visual interaction, private-public conversation and sense of awareness, trust and interruption.

Social media has various types. Popular types are wikis (e.g. Wikitravel), blogs (e.g. Travelblog) and microblogs (e.g. Twitter), social network sites (e.g. Facebook), mediasharing sites (e.g. Flickr, YouTube), review sites (e.g. TripAdvisor) and voting sites (e.g. Digg) (Munar \& Jacobsen, 2014). The focus of this study is on social networks and media-sharing platforms.

\section{Content sharing and photo sharing}

As mentioned above, social media is a term that refers to applications and computer-mediated communication technologies that allow and expect users to participate in the generation and sharing of content (Osatuyi, 2013; Shaw \& Krug, 2013). The use of aforementioned new technologies, have brought up new behavioural tendencies, such as searching online, living online, learning online, shopping online and executing commonplace actions, exploring hundreds of mobile apps (Amaral, Tiago, \& Tiago, 2014).

The internet as a participatory platform allows people to become the 'media' themselves and act as social sensors, voluntarily providing data and information that captures their everyday experiences, and offering various observations on both the physical world and the online world (Leung, Law, Van Hoof, \& Buhalis, 2013; Silva, Vaz De Melo, Almeida, \& Loureiro, 2014). Access to such a large amount of social data can make new forms of information available that were not obtainable through any traditional data collection methods. This data can be used for research in different disciplines or to enhance decision making processes (Silva et al., 2014).

Constant participation and content sharing from individual members are usually an innate part of online communities in order to remain active. Therefore, it is important to understand what motivates people to share content with others (Nov \& Ye, 2008). Munar and Jacobsen (2014) state three motivations for sharing online-content:

- Individual action and personal cognition;

- Self-centred motivations;

- Community-related motivations.

The user-generated content is a valuable form of data that has been voluntarily generated without a direct link to monetary profit or commercial interest (Lu \& Stepchenkova, 2014). The data is valuable since it gradually grows from real and shared experiences, representing the viewpoint of the community which one identifies himself/herself with. Therefore, user-generated content can be termed as a new kind of 'macro-thoughts' generated from "real and shared experiences, representing the point of view of the community which one identifies themselves with" (Sarzotti, 2011, p. 327).
Social computing services provide diverse opportunities for users to interact and different types of user generated content are shared in different venues. Some examples are codes (e.g., open source software), factual content (e.g., Wikipedia), meta-information (e.g., tags), and photos (shared on systems such as Flickr) (Nov, 2009).

In photo sharing platforms, users upload their personal photos and share them online asking other people to comment or rate their content. This has led to a rising volume of publicly available photos (Ivanov, Vajda, Lee, Goldmann, \& Ebrahimi, 2012). More than 500 million photos are uploaded into social networking services every day. The nature of these digital snapshots has attracted a great attention. It is almost a unanimous agreement among scholars that these shared photos are both intimate and realistic in comparison to earlier forms of personal photography (Palmer, 2010). The democratisation of image production and circulation has had a great effect on the way the world is seen, experienced, and remembered (Lo \& McKercher, 2015).

Online photo sharing has been salient in recent years. Online photo sharing services such as Flickr or Instagram enable users to upload, organise, and share their digital photos (Nov \& Ye, 2008). Photo sharing is different from other types of user generated content on Web2.0. People usually take photos regardless of whether they can share it or not. Actually, the 'second act' of uploading and sharing photographs online is an optional action separated from the 'first act' of photo taking (Nov, 2009; Nov \& Ye, 2008).

'Metadata', in the context of user generated content, means further information about information (Wyrwoll, 2014) or data about other data (Lazarinis, 2015). Metadata help users to evaluate content and facilitate the organisation and retrieval of information (Nov, 2009; Wyrwoll, 2014). There are various types of metadata for shared photos and videos such as user-provided tags, comments, geo-tags and capture time (Tang et al., 2012) - some of which could be used for every types of content. Others are specific to a certain social media type (Wyrwoll, 2014).

In case of photos, tags play an important role in changing the way images are organised and shared (Nov, 2009). "Location sharing and annotation refers to collaboratively produced metadata for virtual representations of physical places" (Wyrwoll, 2014). Besides, it assists in searching and managing geo-referenced photos and can reveal the spatial and temporal mobility patterns by tracking the 'digital footprints' of users (Lu \& Stepchenkova, 2014). This study aims to explore geotagged photos as user generated data for architecture and urban design research.

\section{Heritage, tourism and digital technologies}

'Heritage' as a mental construct denotes everything we suppose have been handed down to us from the past (Logan, Kockel, \& Nic Craith, 2016; Lowenthal, 2005; Timothy \& Boyd, 2006). It plays an important role in city image-making processes and is known for its potential to 
improve the identity of urban areas. Heritage is arguably central to social needs and to the preservation of communities in the face of developments, and loss of a heritage site can sometimes compromise or destroy social fabric and community cohesion (Logan et al., 2016; Reeves \& Plets, 2015).

Tourism is sometimes considered a heritage products (Porter \& Salazar, 2005). Heritage tourism is in fact one of the most prominent types of tourism - sport tourism, religious tourism, shopping tourism, adventure tourism, cultural tourism, beach and resort tourism, cruise tourism and heritage tourism - (Timothy \& Boyd, 2006). Tourism is "a leisure activity which presupposes its opposite, namely regulated and organized work. It is one manifestation of how work and leisure are organized as separate and regulated spheres of social practice in 'modern' societies" (Urry \& Larsen, 2011). MacCannell argues (2013) that a tourist acts as a metaphor for modern people's quest for meaning and identity as well as leisure.

'The tourist gaze' is one of the important concepts in tourism industry and means to represent an institutionalised way of looking at places tourists visit, the effect of which is to make the tourism 'product' more digestible to them and thereby easier to sell (Garrod, 2007). By promoting the tourist gaze, tourism is able to perpetuate itself (Garrod, 2007). Urry (1990) describes the concept of 'tourist gaze' as characteristics of landscapes and townscapes that are different to what is experienced in daily Life. Such characteristics are noticeable because they are taken to be in some sense out of the ordinary. "The gaze is constructed through signs, and tourism involves the collection of signs" (Urry \& Larsen, 2011). For example, when tourists see a small village in England, what they gaze upon is the 'real oIde-England'. Urry quotes from Culler: "the tourist is interested in everything as a sign of itself” (Culler in Urry \& Larsen, 2011). In Culler's view, tourists are the unsung armies of semioticians around the world, fanning out in search of the signs of typical Italian behaviour, exemplary Oriental scenes and typical American thruways (Urry \& Larsen, 2011).

Due to its nature, heritage is a social construct within a changing contemporary context (Silberman, 2008). By the advent of new digital media, a technology-driven alternative to preserving cultural heritage has been developed (Kalay, 2008) that is able to support long-term preservation. It is also useful for migration technology to enable the transfer of data into new relationship-encoding formats for the permanent availability of collections information (Cameron \& Robinson, 2007).

Accordingly, the UNESCO Charter on the Preservation of Digital Heritage clarifies the digital heritage as a new legacy: "resources of information and creative expressions are increasingly produced, distributed, accessed and maintained in digital form, creating a new legacy - the digital heritage" (Cameron \& Robinson, 2007).

Digital media is employed for modelling (such as geographic information systems), capturing data (such as geo- physical surveys and laser scanning), and attract different audiences (either through mobile devices, gaming, virtual or augmented reality) in several different contexts, such as schools, cultural tourism, museum visits, and life-long learning (Economou, 2015). This paper focuses on how heritage is perceived through the lens of social media.

\section{Methodology}

The rapid development of technology and the advent of social media in the recent decades have resulted in a growing use of visual forms of communication such as photo sharing. The use of visual research methods has become increasingly widespread throughout various disciplines such as social sciences and built environment. While the use, production and transmission of visual forms of communication have escalated in the past few decades (owing to the social media), the application of visual research methods has also become widespread throughout various disciplines. Content analysis is a methodology for investigating text as well as exploring images (Rose, 2001). This methodology is based on counting and analysing the frequency of certain visual elements in a clearly defined sample of images (Motamed \& Mahmoudi Farahani, 2018).

This paper aims to investigate the historical core of Shiraz and its heritage sites/buildings through the lens of social media users. The research question is: how the historical core of Shiraz has been represented through published imageries on social media? The methodology of this research is an in-depth survey analysis of publicly published images on social media over a year. Through exploring the pattern of shared imageries, this methodology provides an opportunity for investigating popular elements, buildings, and heritage sites of the historical core of Shiraz. Similar to content analysis, to achieve replicable and valid results, the image analysis has been conducted in four steps: (1) finding images, (2) categorising images, (3) coding, and (4) finding patterns.

The first step is to find the key photo sharing media platforms. Therefore, different social media domains were examined in terms of popularity for photo publishing and their number of users. As discussed before, the location that images have been taken from (geo-tagged data) will provide an opportunity to investigate any potential pattern in the selection of photography locations. Therefore, besides the popularity of websites for posting and sharing photos, having a geo-tag option plays a decisive role in the selection of social media platforms. Accordingly, three popular social media domains of Flickr, Instagram and 500PX have been selected as popular platforms for publishing geo-tagged images. Despite their differences in offering their services, all these three websites are popular between users for sharing images. Flicker and 500px are image hosting platforms, which are used as a place to find inspirations and to connect photographers to one another. Instagram provides an opportunity to share 
photos on a variety of social networking platforms such as Flickr ${ }^{1}$. As the images used for this paper are publicly shared in the studied platforms, no conflict of interest was found for analysing and using them for the purpose of this research.

In order to test the methodology, the case study of historical core of Shiraz has been selected and a time period has been employed. All images published during 2015 in the selected platforms (Flickr, Instagram and 500PX) and geo-tagged within the area of the historical district have been downloaded and coded based on their location. As the research question is concerned with the built environment and physical qualities of the city, all irrelevant images to the research question (e.g. personal images) have been excluded from the database and coding.

The analysis occurs in two stages. Firstly, the heritage sites will be investigated in regard to their number of photos geotagged and published in these websites. The number of images can be considered as a representation of the way visitors interpret, remember and celebrate these heritage sites. It also reinforces what media can create as a perception of a heritage site in historic cities.

Mapping the location of the published photos in the old district of Shiraz produces a virtual map of heritage sites. This map represents the way the old city has been perceived and at the same time specifies the neglected heritage sites that are missing. The missing spots themselves tell a story of oblivion, a story of how a heritage site or building might be highlighted or devalued through social media and the lenses of everyday photographers.

In the second stage, the site with the highest number of published images will be explored in detail to examine the physical and spiritual qualities of a heritage site that contribute to its popularity among social media photographers.

\section{Study area}

The city of Shiraz is more than 2000 years old. It is the fifth most populous city in Iran and serves as a fine example of Iranian old cities in the hot and arid climate. The city is located 895 kilometres south of Tehran (the capital city of Iran) and 100 kilometres north of the Persian Gulf.

Shiraz history extends to the pre-Islamic era. Its formal architecture, the shape of its houses and street network, and elements like the covered bazaar, mosques and shrines, have contributed to the image of Shiraz as a typical Islamic city in Iran. Cuneiform records from the great

\footnotetext{
1 To download the social media photos, Current Location Website (http://current-location.com/) was used. Current Location is a web app that makes it possible to view geo-tagged pictures made with Instagram, Flickr and 500px based on any position in the world. An area of one square kilometre which comprises the historical core of Shiraz was studied. All photos in this area were downloaded manually and coded based on their location on the map.
}

ceremonial capital of Persepolis show that Shiraz was a significant township in Achaemenian times. However, the city became provincial capital only in 693 A.D, after the Arab armies conquered Estakhar, the nearby Sassanian capital. As Estakhar fell into decline, Shiraz grew in importance under the Arabs and several local dynasties. The Buyids (945 to 1055) made it their capital - building mosques, palaces, a famous library and a great city wall. The city was spared destruction by invading Mongols when its local ruler offered tributes and submission to Genghis Khan.

Throughout the Safavid Empire (16-17 century), Shiraz remained a provincial capital and Emam Qoli Khan, the governor of Fars under Shah Abbas I, constructed many palaces and ornate buildings in the same style of those built in the same period in Isfahan, the capital of the Empire. According to historical sources such as traveller's memoirs, the structure of the city in the Safavid period was based on an organic configuration. The city map of this period shows that the old district is clearly the most integrated place in the city, which coincides with the geographical centre of the city as well. The city was characterized by 11 distinct neighbourhoods inhabited by separate communities with powerful social cohesion. The physical construct of these neighbourhoods has, to a large extent, remained intact. The most significant feature of each neighbourhood is a neighbourhood centre usually consisting of a square, local market and a building with a religious function. These 11 neighbourhoods (representing the historical core of Shiraz) have been selected as the case study of this research. These neighbourhoods have been emerged gradually, based on socioeconomic, religious, occupational, ethnic and environmental factors (Figure 1).

\section{Analysis}

As discussed above, the first stage of analysis seeks to identify the heritage buildings and sites which have been geotagged on the selected social media websites. Therefore, all buildings with at least one photo in the three selected
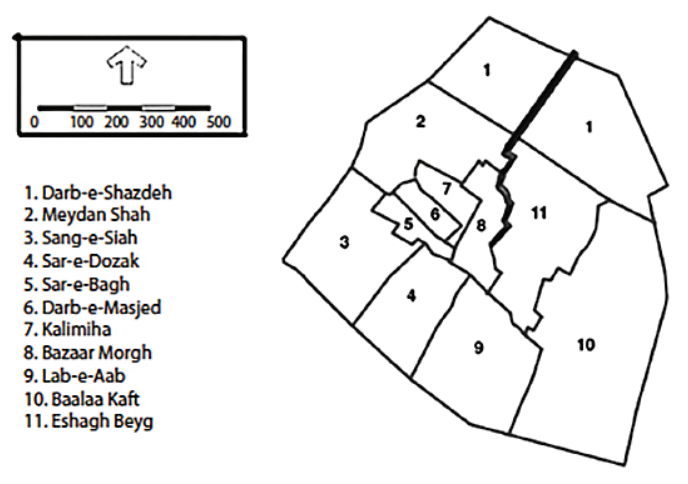

Figure 1. The map of Shiraz historical neighbourhoods (source: Mahmoudi Farahani \& Lozanovska, 2015) 


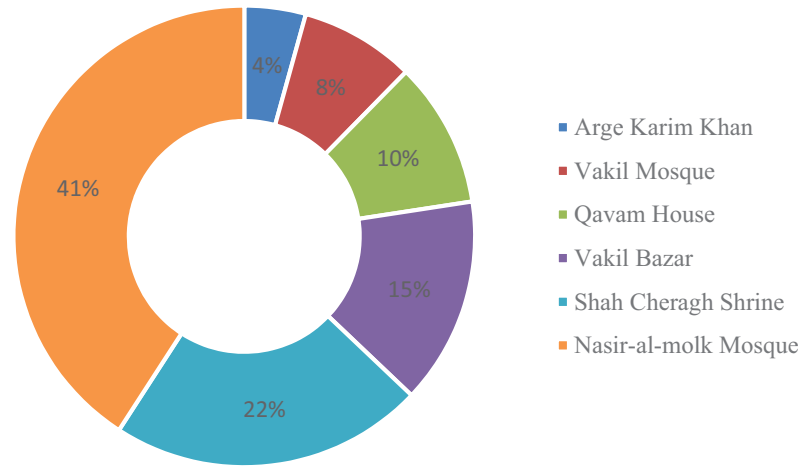

Figure 2. Percentage of the number of published photos from different heritage sites

platforms have been carefully mapped. The buildings with at least one image are Arge Karim Khan, Nasir-al-Molk Mosque, Qavam House, Shah Cheragh Shrine and Vakil Bazar, Vakil Bath and Vakil Mosque.

As the chart below (Figure 2) illustrates, the ratio of the number of published photos from these historical sites varies considerably. Nasir-al-Molk Mosque with 76 photos is in the first place followed by Shah Cheragh Shrine and Vakil Bazar. Whereas the two first buildings have a religious character and function, Vakil Bazaar is the oldest market in the city functioning as a trade Centre.

The question to be asked here is: what makes these places so popular for photographers and social media users in comparison to other heritage sites in the historical core of the city. Function cannot be the only explanation, as there are several other historic buildings located in the historic core of the city with a similar function. The heritage character and their antiquity also cannot be the only reason, as there are a number of older sites in the city

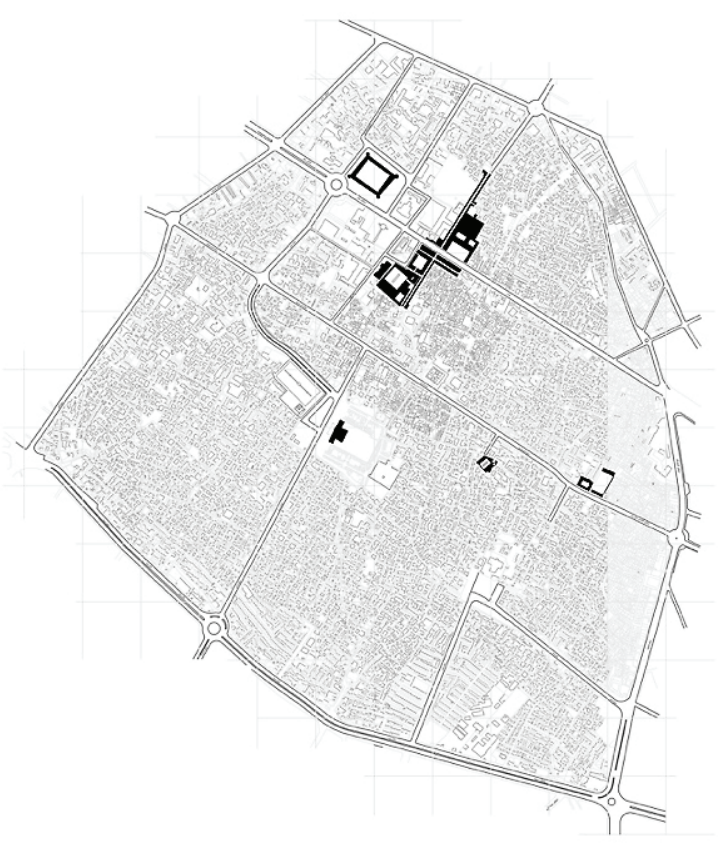

Figure 3. the places with published photos on social media without any published photo. The architectural qualities of historic sites have indeed had a contributing effect as most photos have focused on and showcased the architectural qualities of these edifices. Therefore, published photos usually represent an amalgamation of architectural qualities and the atmosphere of the space together with the functionality and the historic character of the site or building.

Visitors' knowledge about the history of these sites is a matter of question and beyond the scope of this study. As Connerton (1989, p. 2) argues: "our experience of the present very largely depends on our knowledge of the past". Understanding whether a knowledge of the history has contributed to the pattern of remembering and negligence can inform the conservation plans and strategies to preserve these historical sites.

The map below demonstrates the sites with at least a photo in the historic core of Shiraz (Figure 3). As the map illuminates, only a few sites (seven sites) had a photo publicly published in the three selected platforms. Most of these seven sites are a part of the Vakil Complex built in the Zand Dynasty. Not only the map below highlights the significant and popular sites (in the perception of social media users), but also it underlines the huge proportion of the old city which has been overlooked and neglected.

ICHHTO (Iran Cultural Heritage, Handcrafts and Tourism Organization) annually publishes a list of protected and historically valuable sites in Iranian cities such as Shiraz. Currently the list includes 93 sites with various functions and ages within the historic core of the city. The map below (Figure 4) represents the story of the oblivion, the historic sites from the ICHHTO's list which have not been published in the social media.



Figure 4. The map of the oblivion based on the Iran Cultural Heritage, Handcrafts and Tourism Organization list 
As the map of oblivion shows, the old city is occupied by historic sites of different sizes and functions. However, there is a small fraction of these treasured edifices which have been appreciated via the lenses of social media users. Interestingly, this small fraction encompasses a huge percentage of the published photos. The map below illustrates the placement of the 86 left heritage sites which were neglected, unloved or simply forgotten.

Among the seven buildings (which photos have been broadcasted), a significant percentage of the published photos $(40 \%)$ have been geotagged in the Nasir-alMolk Mosque. This study will investigate Nasir-al-Molk Mosque's photos in detail, in order to find out the qualities of this historic site which contributes to its popularity and social media recognition.

\section{Nasir-al-Molk Mosque}

Nasir-al-Molk Mosque, also known as the Pink Mosque, is a traditional mosque in the historical district of Shiraz. It is located in the district of Gowd-e-Arabaan, near ShahCheraq Shrine. The mosque includes extensive coloured glasswork in its internal façade (central courtyard façade) and displays other traditional elements such as Panj-Kase (five concaved) design. It is locally known as the Pink Mosque due to the usage of considerable pink colour tiles for its interior design which has not been common in previous traditional mosques.

The mosque was built during the Qajar era $\left(18^{\text {th }}\right.$ century) and is still in use for its original religious function and also as a tourist attraction. The inscription of its entrance corridor indicates the initial date of its construction as 1293 and 1305 as the completion date. Another inscription which exists in the main Iwan (veranda) of the edifice dates back to 1299 (Haji-Ghasemi, 2004). Mirza-Hassan-AliKhan Nassir-al-Molk was a Qajar ruler in Shiraz who commissioned the mosques to be built in his era. The names of Mohammad-Hassan Memar, the architect in charge of its construction and Mohammad-Hossein Naqqash-Shirazi, the designer of its tilework are mentioned in the inscriptions of the mosque (Haji-Ghasemi, 2004).

Qajar era was the beginning of a conflict between tradition and modernity in Iran which caused a fundamental change in all aspects of Iranian life as well as architecture (Bomanian, Momeni, \& Soltanzadeh, 2011). The growth of a relationship between Iran and Europe, which was started with the travel of Naser al-Din Shah to Europe, resulted in a profound social and cultural effect on Iranian society. Moreover, familiarity with Western art and architecture through sending students to European countries and the use of Western artists and architects in new developments intensified the influence of Western perspective on Iranian's art and architecture. Resultantly, delicate crafts such as mirrorwork and tilework were thrived in the era (Jaafarloo, 2015). Moreover, the arrival of photography in Iran during Qajar era had a specific impact on tilework and decorating motifs replacing arabesque and abstract motifs of foliage by photographic portraits of important figures of the country, buildings, landscapes and images of animals (Bomanian et al., 2011).

Different materials such as tile, brick, stone or plaster have been used in this mosque. Although some of these materials and decoration techniques were common in Iranian mosques of that time, but the use of Western decorations alongside Iranian decorations was not common before Nasir-al-Molk. Three types of decoration techniques inspired both by traditional and Western decoration styles have been used in Nasir-al-Molk Mosque: (1) Abstraction or Arabesque which were inspired by plant form and nature; (2) building images which were inspired by European buildings and churches; (3) written verses of the Holy Quran or Hadith in Kofi, Sols, Banaiand and rarely Nastaliq calligraphy. The rainbow colour tiles, Resmes bandi, Mogharnas, and Qatar Bandi are other examples of traditional decorations that have been use in this mosque. Therefore, the diversity and vast number of decorations is one of the unique features of Nasir-al-Molk Mosque (Oghabee, 1999).

\section{The Analysis of Nasir-al-Molk published photos}

This section of analysis is assigned to the study of published photos, which were geotagged on the site of the Nasir-al-Molk Mosque. These photos were carefully explored by authors to uncover the themes, topics and ideas that they present in the social media. Four general themes were discovered among the photos: the spatial presentation of different spaces, the architectural qualities of different elements (such as ceilings, walls, doors), the atmosphere/ character of the space, and colour/light features.

\section{Coding based on different rooms/spaces as photo subjects}

One of the themes that came up in the study of published imageries was the representation of the spatial qualities of different spaces in Nasir-al-Molk Mosque. The downloaded photos from social media were coded in different groups based on the space (room) that they capture (Figure 5 and 6). The photos, therefore, were categorized in 6 groups including east shabestan (seraglios), west shabestan, iwan, ravaagh, the internal yard and pool. As the mapping below illustrates, the west shabestan is the most published space with 21 photos and the east shabestan is the least published space with only one photo geotagged in the time period and online platforms investigated in this study.

Generally, both iwan and shabestan are large flexible spaces in mosques that are used for praying and other religious purposes. In their historic sense, they were also used as educational spaces, where there was not a separate school around the mosque. Since, these spaces were usually covered with rugs and they did not have any furniture, they were sufficiently flexible to accommodate educational and religious purposes. 


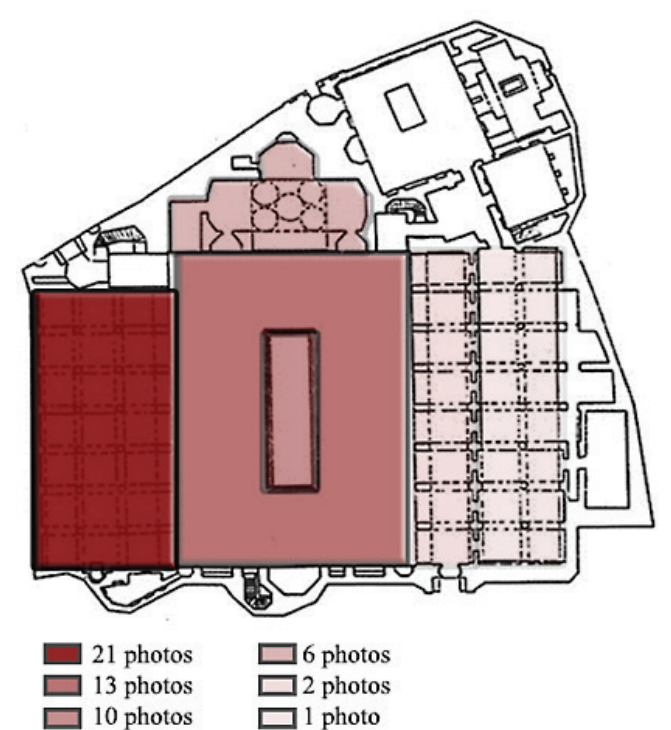

Figure 5. Nasir-al-Molk Mosque photos of different spaces

\section{Space elements}

The review of Nasir-al-Molk photo subjects (74 geotagged images) reveals the pattern of photographers and social media users' interests in different elements of this mosque. The patterns of spatial interest have been divided into three groups: 1. tiling on walls and ceilings (31 images); 2. windows (22 images); and 3. columns (24 images).

Tiling as a photo subject accounted for $16.94 \%$ of the shared images (Figure 7). The rainbow (seven-colour) tiles and the dominance of pink in tiles are unique features of this mosque, which have captured the attention of social media users. Majority of the mosque's surfaces have been covered by rainbow tiles with plant design patterns. The social media images have been taken from different parts of these surfaces specially the tilework on the walls of the west shabestan. The images that have been coded as tilework are mostly focused on different techniques of tiling and decoration such as Rasme-bandi, Mogharnas and Qatar-bandi. Moreover, they illustrate different types of motifs such as natural flowers and plants, buildings and
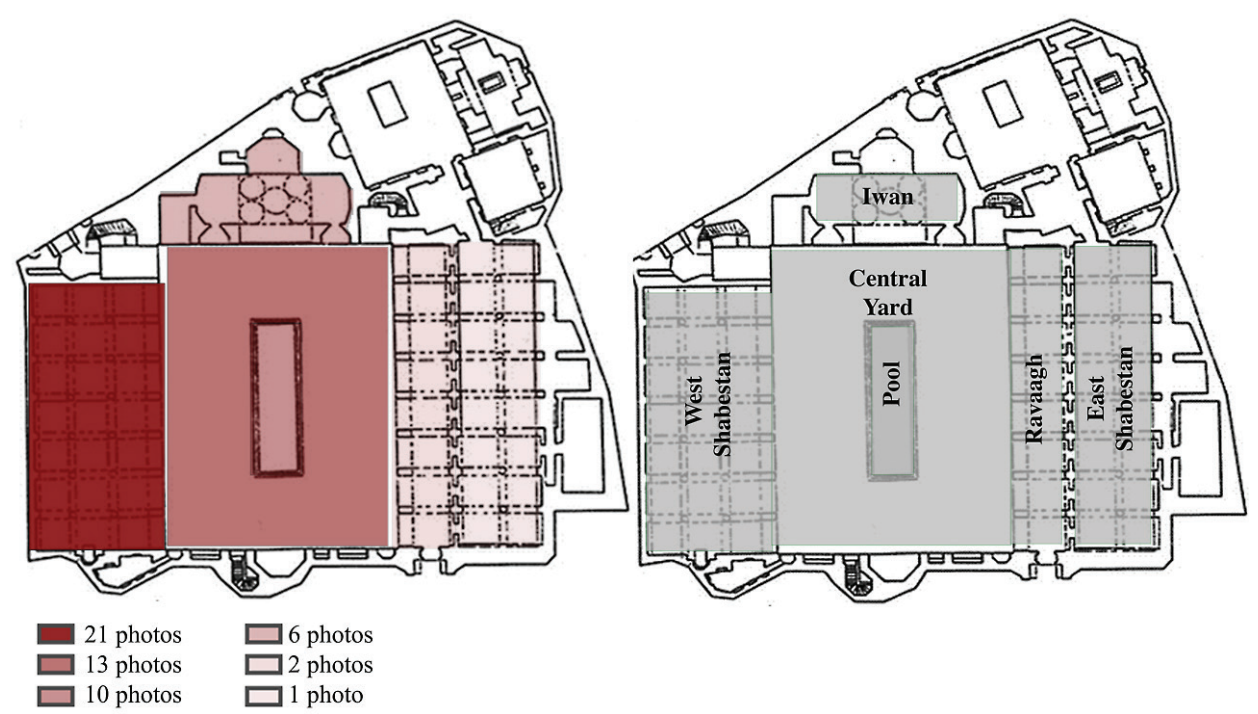

Figure 6. Nasir-al-Molk Mosque published photos based on different rooms and spaces
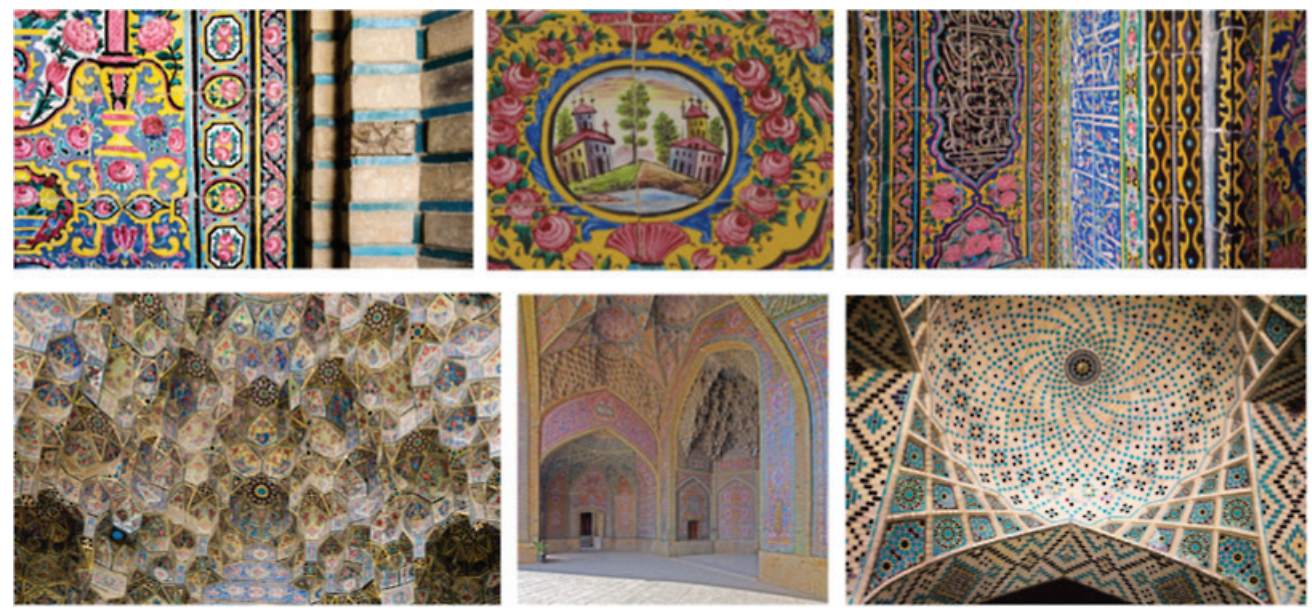

Figure 7. Tilework 
animal figures (which were inspired from Western world) with different colour palettes such as pink, blue, yellow, white and grey. Inscriptions of Quran verses in the format of Sols calligraphy can also be seen in some of the published images.

Colourful glasses of this mosque were the subject of $12 \%$ of shared images. The use of colourful glasses in the design of windows and doors of the west shabestan is a unique feature of this mosque (Figure 8). Therefore, most of the published images coded in this section have been taken from the west shabestan. This space encompasses seven doorways, which open to the mosque's central courtyard. Each doorway has a vault form made from wood decorated by colourful glass windows (Oghabee, 1999). The reflection of sunlight through colourful windows and doors in this shabestan creates a wonderful scene on the floor. However, there is no image from windows and doors of the east shabestan, as its windows and doors do not have specific decorations or colourful glasses.

Columns as important elements of the shabestan were the subject of 19 images (13\%). The shared images from columns were mostly focused on columns of the west shabestan (Figure 9). The images show spiral carved columns not only as a strong structural element but also as a decorative element. In some images, the row of columns was utilised as a subject to stress the perspective and depth in the captured space. Additionally, columns were sometimes used to define the border of the subject in photography.

\section{Spiritual atmosphere}

Architecture generates atmospheres in all spaces. The atmosphere of a building refers to the sensory qualities that they may emit. Atmospheres can be produced, in a sense that physical characteristics can be staged strategically or instrumentally in ways that affect how people experience a space (Bohme, 2014). Architectural characteristics of a space generate its atmosphere. Atmospheres emanate from things and persons and emerge from the daily life of inhabitants (Bohme, 2014). Users perceive or experience spaces through their emotional sensibility (Zumthor, 2006). According to Bohme (2014), atmospheres fill spaces; they emanate from things, assemblages of things and persons.

Some of the photos taken from Nasir-al-Molk illustrate and stress its spiritual atmosphere. This atmosphere as a photo subject accounted for $7.65 \%$ of shared images (14 images). In some images, the sense of spirituality has been reinforced via a persona conducting a religious ritual (such as praying) or dressed in religious clothing (Figure 10). Interestingly, all these photos were taken inside the west shanbestan, which embodies the most number of decorations.

Colourful tiling and lighting of the west shabestan has generated a unique spiritual atmosphere in the mosque. The play of colour, light and shadow in combination with human figures (mostly in praying position) depicts special moments of communication between human and spiritual world. It seems that the reflection of colours on human
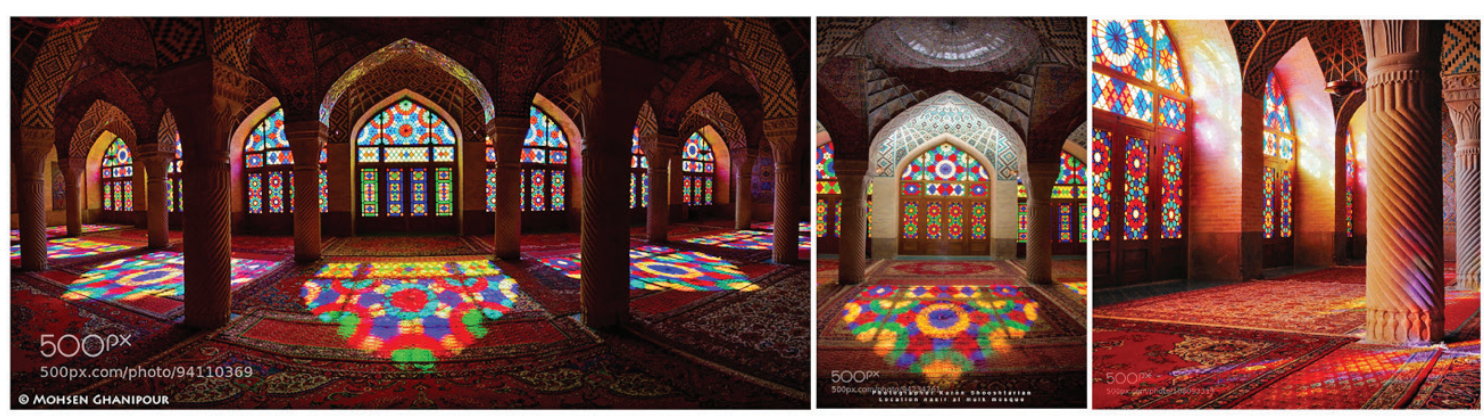

Figure 8. Glasswork
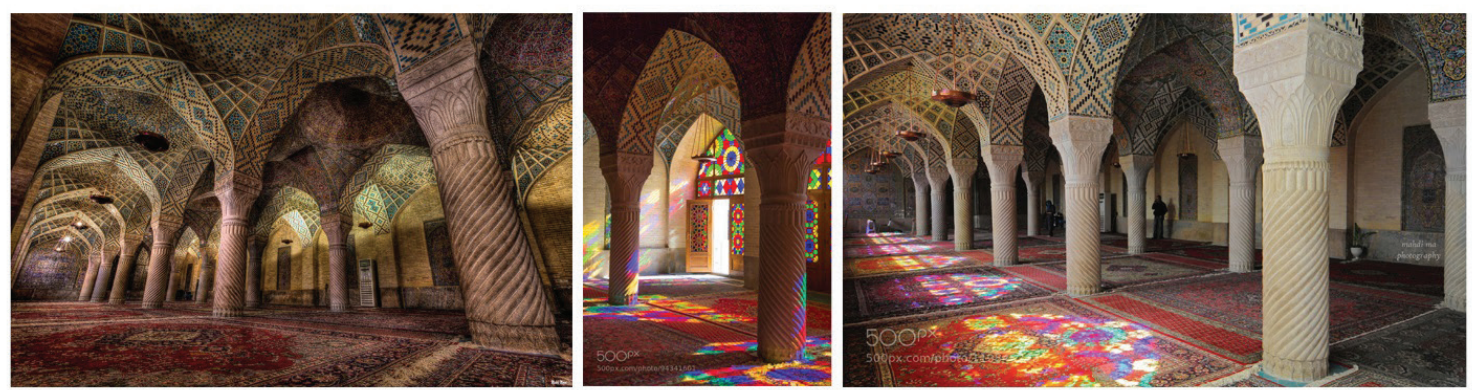

Figure 9. Columns 

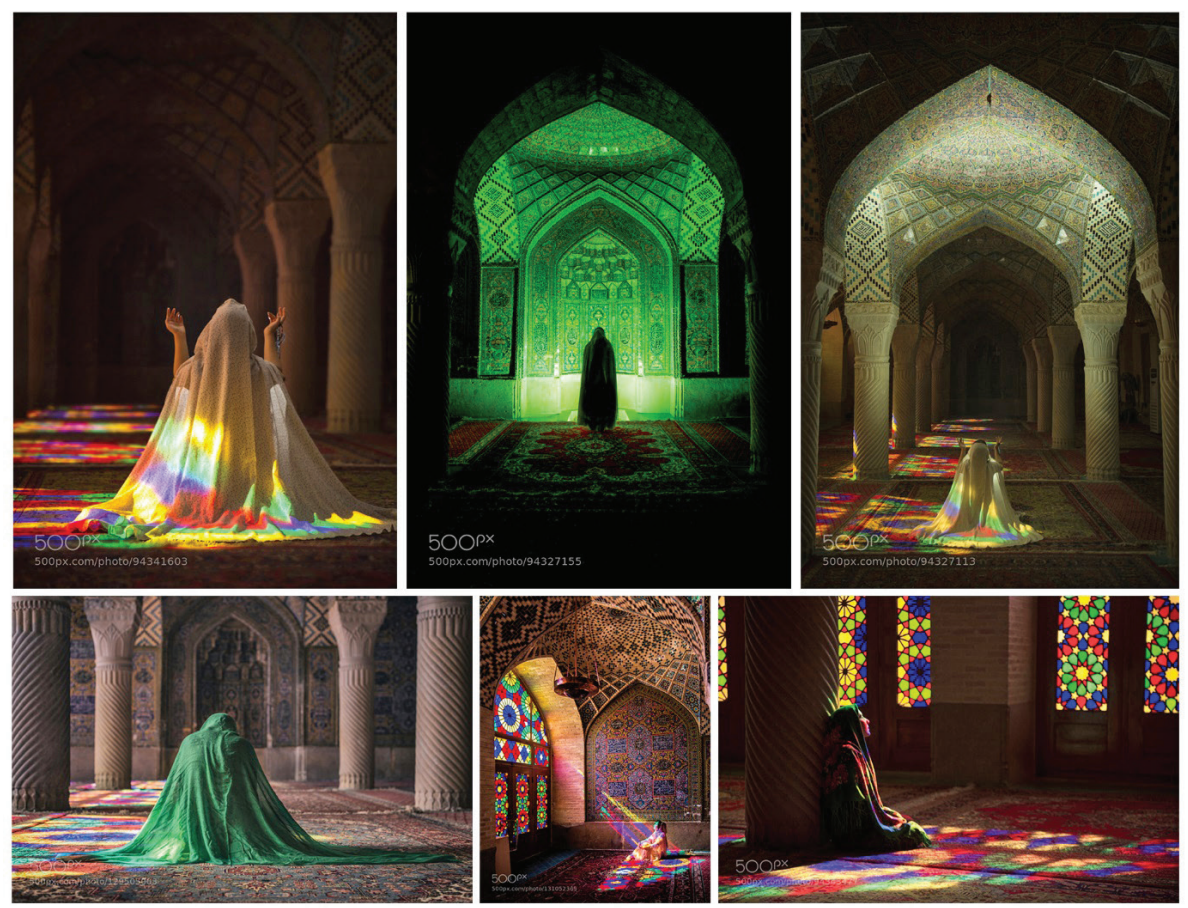

Figure 10. Spiritual atmosphere
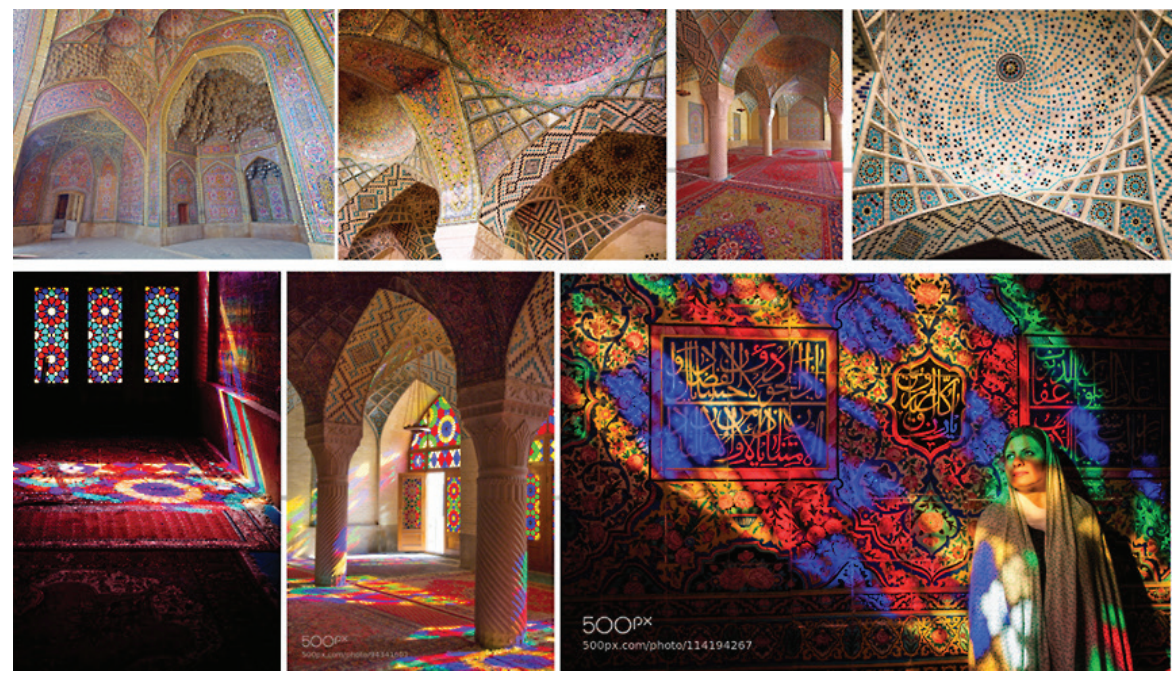

Figure 11. Colour and light

figures, playing with light and portraying praying figures have visualised the spiritual atmosphere of Nasir-al-Molk for social media users.

\section{Colour and light}

Natural light, shadow and colour have been always important elements of Iranian Architecture and especially Islamic philosophy and ideology. As mentioned before, the presence of natural light and the way it enters the space have been considered as a spiritual aspect of the place in addition to its religious function. In other words, colours and light have generated a sacred identity for the west shabestan and the whole mosque.
The use of natural light in mosques is known as a mystical symbol and a sign of the presence of God (Bemanian \& Nikoudel, 2014). However, the way natural light is used and the play of lights, shadows and colours have changed throughout the history of Iranian architecture based on the philosophy of designers and the level of importance of decoration in the dynasty. Therefore, light-catching elements such as openings, doors and windows have been used in mosques not only to enter light into the space but also to create a spiritual environment for prayers through controlling the amount of light and its quality. Majority of Qajar era buildings are known for their innovative lighting and colouring techniques. Among them, Nasir-al-Molk Mosque is known for its variety of decoration and unique 
lighting and colour palette dominated with pink colour. Therefore, Nasir-al-Molk is a good representative of decorative tendencies and innovative lighting techniques in the Qajar Era. The elegant play of light and colour in Nasir-alMolk has attracted the attention of many photographers and social media users. It accounts for $32.24 \%$ of published images across the investigated platforms.

Figure 11 shows the innovative lighting technique, the use of colourful glass filters and controlling the amount of light and shadow with the use of geometric apertures. The rainbow tiles with their unique colour palette (pink, blue, yellow, white and grey), and the reflection of sunlight by colourful glasses in the west shabestan windows were the subject of 59 images taken from this mosque.

\section{Conclusions}

Social media networks as rich and trustworthy information sources can be used by tourists in order to manage, plan, share, and annotate their trip experiences. Images as strong mediums reflect the main parts of a travel and the characteristics that tourists gaze upon.

The emergence of social media and prevalence of its use have encouraged researchers in different disciplines to employ social media as a new source of data in their studies. Accordingly, the analysis of the accumulation of individual images in online public platforms may allow architects and urban designers to investigate social media users' perceptions of and experience in cities.

The social media illustrates an evaluative image of the built environment and the elements that people want to remember, publish and share. The published images can show which places have captured the attention of social media photographers and at the same time which ones are undervalued and underrated. Understanding how people are attracted by different attributes of the built environment can shed light on why a heritage site is popular or not and what are visitors' perceptions and attitudes towards them. Such research can inform heritage management practices in order to preserve and celebrate heritage sites.

In this paper the historic core of the city of Shiraz was investigated. The findings of this study showed that in the historic core of Shiraz, heritage buildings were the most popular photo subject in the investigated platforms. However, the ratio of published photos from these historical sites varied considerably. Among these buildings, Nasir-al-Molk Mosque is the most photographed building, which accounts for $40 \%$ of the photos. Therefore, this study explored Nasir-al-Molk as a case study to uncover the reasons behind its popularity on social media and to investigate what makes this building unique and different from several other heritage buildings that are located in a close distance.

Through a careful survey of images taken from Nasiral-Molk, its west shabestan was identified as the most photographed space. The qualities of this prayer room and its unique tiling and colourful glasswork have made it a popular subject for social media photographers. Interestingly, the physical qualities of this room have highlighted its spiritual atmosphere and several photographers have emphasised on its holiness and spiritual character through adding a praying persona to the scene. These photos have accentuated the sense of place and framed the physical features that contribute to the specific atmosphere of this place.

The published imageries on social media can be representative of public taste and perception. The analysis of buildings and urban spaces through the lens of social media is a new methodology that can be employed by architects and urban designers to investigate the most/least attractive areas in a city or even in a building. Although the analysis of social media images alone may not justify an environmental change due to its limitations, it should not be overlooked since it is a minor concern or a matter of taste. This methodology can also help researchers to register the changes and urban interventions, through monitoring the emerging patterns in social media images over time.

\section{References}

Akpan, U., Akwaowo, E., \& Senam, N. (2013). Uses and gratifications of social networking websites among youths in Uyo. International Journal of Asian Social Science, 3, 353-369.

Amaral, F., Tiago, T., \& Tiago, F. (2014). User-generated content: tourists' profiles on TripAdvisor. International Journal of Strategic Innovative Marketing, 01, 137-147.

Andzulis, J. M., Panagopoulos, N. G., \& Rapp, A. (2012). A review of social media and implications for the sales process. Journal of Personal Selling and Sales Management, 32, 305316. https://doi.org/10.2753/PSS0885-3134320302

Anuradha, P. (2015). A frame work for preserving privacy in social media using generalized Gaussian Mixture Model. International Journal of Advanced Computer Science and Applications, 6, 68-71. https://doi.org/10.14569/IJACSA.2015.060711

Ariel, Y., \& Avidar, R. (2015). Information, interactivity, and social media. Atlantic Journal of Communication, 23, 19-30. https://doi.org/10.1080/15456870.2015.972404

Bemanian, M. R., \& Nikoudel, F. (2014). Evaluation of daylightcatching and daylight providing methods in MOSQUES. Journal of Researches in Islamic Architecture, 1(3), 60-74.

Bohme, G. (2014). Urban atmospheres: charting new directions for architecture and urban planning. In C. Borch (Ed.), Architectural Atmospheres: on the experience and politics of architecture (pp. 42-59). Birkhauser.

Bomanian, M. R., Momeni, K., \& Soltanzadeh, H. (2011). Study the innovations and developments of tile decorations and motifs in Mosques-schools of Qajar Era. Scientific and Research Journal of Negareh, 18.

Boyd, D., \& Heer, J. (2005). Vizster: visualizing online social networks. Paper presented at the Proceedings of the International Symposium on Information Visualization (InfoVis'05). Minneapolis, Minnesota.

Cameron, F., \& Robinson, H. (2007). Digital knowledgescapes: cultural, theoretical, practical, and usage issues facing museum collection databases in a digital epoch. In F. Cameron \& S. Kenderdine (Eds.), Theorizing digital cultural heritage: a critical discourse (pp. 165-191): MIT Press Scholarship Online. 
Chen, H., \& Kelliher, A. (2011). Conversational lives: visualizing interpersonal online social interactions. Online Communities and Social Computing, 6778, 241-250.

https://doi.org/10.1007/978-3-642-21796-8_26

Connerton, P. (1989). How societies remember. Cambridge: Cambridge University Press.

Economou, M. (2015). Heritage in the digital age. A companion to heritage studies, 215-228. https://doi.org/10.1002/9781118486634.ch15

Fotis, J., Buhalis, D., \& Rossides, N. (2012). Social media use and impact during the holiday travel planning process. Information and Communication Technologies in Tourism, 1-12.

Garrod, B. (2007). A snapshot into the past: the utility of volunteer-employed photography in planning and managing heritage tourism. Journal of Heritage Tourism, 2, 14-35. https://doi.org/10.2167/jht018.0

Gruzd, A., Staves, K., \& Wilk, A. (2011). Tenure and promotion in the age of online social media. Paper presented at the Proceedings of the American Society for Information Science and Technology. New Orleans, LA.

Haji-Ghasemi, K. (2004). Mosques: Rozaneh * Beheshti University.

Heinrichs, J. H., Lim, J. S., \& Lim, K. S. (2011). Influence of social networking site and user access method on social media evaluation. Journal of Consumer Behaviour, 10, 347-355. https://doi.org/10.1002/cb.377

Ivanov, I., Vajda, P., Lee, J.-S., Goldmann, L., \& Ebrahimi, T. (2012). Geotag propagation in social networks based on user trust model. Multimedia Tools and Applications, 56, 155-177. https://doi.org/10.1007/s11042-010-0570-7

Jaafarloo, M. E. (2015). Reviewing Qajar era architectural decoration with an emphasis on European designs in the works of Shiraz. Cumhuriyet University Faculty of Science (CSJ), 36(4).

Junco, R., \& Chickering, A. W. (2010). Civil discourse in the age of social media. About Campus, 15, 12-18. https://doi.org/10.1002/abc.20030

Kalay, Y. E. (2008). Preserving cultural heritage through digital media. In Y. Kalay, T. Kvan, \& J. Affleck (Eds.), New heritage: new media and cultural heritage (pp. 01-10). Routledge.

Kaplan, A. M., \& Haenlein, M. (2010). Users of the world, unite! The challenges and opportunities of social media. Business Horizons, 53, 59-68.

https://doi.org/10.1016/j.bushor.2009.09.003

King, L., Stark, J. F., \& Cooke, P. (2016). Experiencing the digital world: the cultural value of digital engagement with heritage. Heritage \& Society, 9(1), 76-101. https://doi.org/10.1080/2159032X.2016.1246156

Lazarinis, F. (2015). Cataloguing and classification: an introduction to AACR2, RDA, DDC, LCC, LCSH and MARC 21 Standards. Cataloguing and Classification, 225-232. https://doi.org/10.1016/B978-0-08-100161-5.00012-9

Leung, D., Law, R., Van Hoof, H., \& Buhalis, D. (2013). Social media in tourism and hospitality: a literature review. Journal of Travel \& Tourism Marketing, 30, 1-2. https://doi.org/10.1080/10548408.2013.750919

Lo, I. S., \& McKercher, B. (2015). Ideal image in process: online tourist photography and impression management. Annals of Tourism Research, 52, 104-116. https://doi.org/10.1016/j.annals.2015.02.019

Logan, W., Kockel, U., \& Nic Craith, M. (2016). The new heritage studies: origins and evolution, problems and prospects. $A$ companion to heritage studies, 1-25.
Lowenthal, D. (2005). Natural and cultural heritage. International Journal of Heritage Studies, 11(1), 81-92.

https://doi.org/10.1080/13527250500037088

Lu, W., \& Stepchenkova, S. (2014). User- generated content as a research mode in tourism and hospitality applications: topics, methods, and software. Journal of Hospitality Marketing \& Management, 119-154.

https://doi.org/10.1080/19368623.2014.907758

MacCannell, D. (2013). The tourist: a new theory of the leisure class: Univ of California Press.

Mahmoudi Farahani, L., \& Lozanovska, M. (2015). The social life of historical neighbourhoods: case study of a Middle Eastern city, Shiraz. Journal of Architecture and Urbanism, 39(3), 176187. https://doi.org/10.3846/20297955.2015.1088416

Malita, L. (2011). Social media time management tools and tips. Procedia Computer Science, 3, 747-753.

https://doi.org/10.1016/j.procs.2010.12.123

Motamed, B., \& Mahmoudi Farahani, L. (2018). The evaluative image of the city through the lens of social media: case study of Melbourne CBD. Journal of Architecture and Urbanism, 42(1), 24-33.

Munar, A. M., \& Jacobsen, J. K. S. (2014). Motivations for sharing tourism experiences through social media. Tourism Management, 43, 46-54. https://doi.org/10.1016/j.tourman.2014.01.012

Nov, O. (2009). Information sharing and social computing: why, what, and where? Advances in Computers, 76, 1-18. https://doi.org/10.1016/S0065-2458(09)01001-8

Nov, O., \& Ye, C. (2008). Community photo sharing: motivational and structural antecedents. Twenty Ninth International Conference on Information Systems. Paris, 2008.

Oghabee, M. M. (1999). Encyclopedia of monuments in Iran in Islamic period/ 3, Historical Mosques. Tehran: Hozeye Honari.

Osatuyi, B. (2013). Information sharing on social media sites. Computers in Human Behavior, 29, 2622-2631. https://doi.org/10.1016/j.chb.2013.07.001

Palmer, D. (2010). Emotional archives: online photo sharing and the cultivation of the self. Photographies, 3, 155-171. https://doi.org/10.1080/17540763.2010.499623

Porter, B. W., \& Salazar, N. B. (2005). Heritage tourism, conflict, and the public interest: an introduction. International Journal of Heritage Studies, 11(5), 361-370.

Reeves, K., \& Plets, G. (2015). Social needs and community identity. A Companion to Heritage Studies, 15, 203. https://doi.org/10.1002/9781118486634.ch14

Rose, G. (2001). Visual methodologies: an introduction to the interpretation of visual materials. London: Thousand Oaks, Calif: Sage Publication.

Sarzotti, M. (2011). Increasing the value of cultural heritage by using social media. Design Principles and Practices: An International Journal - Annual Review, 5. https://doi.org/10.18848/1833-1874/CGP/v05i06/38210

Shankar, R. (2011). Factors influencing online social interactions. Paper presented at the Online Communities and Social Computing. Orlando, FL, USA.

Shaw, A., \& Krug, D. (2013). Heritage meets social media: designing a virtual museum space for young people. Journal of museum education, 38, 239-252.

https://doi.org/10.1080/10598650.2013.11510774

Silberman, N. (2008). Chasing the unicorn? The quest for 'essence in digital heritage. In Y. Kalay, T. Kvan, \& J. Affleck (Eds.), New heritage: new media and cultural heritage. Routledge. 
Silva, T. H., Vaz De Melo, P. O. S., Almeida, J. M., \& Loureiro, A. (2014). Large-scale study of city dynamics and urban social behavior using participatory sensing. Wireless Communications, IEEE, 21, 42-51.

https://doi.org/10.1109/MWC.2014.6757896

Tang, J., Wang, M., Hua, X. S., \& Chua, T. S. (2012). Social media mining and search. Multimedia Tools and Applications, 56, 1-7. https://doi.org/10.1007/s11042-011-0822-1

Timothy, D. J., \& Boyd, S. W. (2006). Heritage tourism in the 21st century: valued traditions and new perspectives. Journal of heritage tourism, 1(1), 1-16. https://doi.org/10.1080/17438730608668462

Treem, J. W., \& Leonardi, P. M. (2012). Social media use in organizations: exploring the affordances of visibility, editability, persistence, and association. Communication yearbook, 36, 143-189.
Urry, J. (1990). The tourist gaze. Leisure and travel in contemporary societies. Collection theory, culture \& society. London: Sage Publications.

Urry, J., \& Larsen, J. (2011). The tourist gaze 3.0: Sage.

Wyrwoll, C. (2014). Social media: fundamentals, models, and ranking of user-generated content. Wiesbaden: Springer Vieweg.

Zhou, L., \& Wang, T. (2014). Social media: a new vehicle for city marketing in China. Cities, 37, 27-32. https://doi.org/10.1016/j.cities.2013.11.006

Zumthor, P. (2006). Atmospheres: architectural environments; surrounding objects: Boston: Birkhäuser. 